\title{
Spectral Characteristics of Tobacco Cultivars with Different Nitrogen Efficiency and Its Relationship with Nitrogen Use
}

\author{
Taibo Liang, Jianwei Wang, Yanling Zhang, Jiaqin Xi, Hanping Zhou, \\ Baolin Wang, and Qisheng Yin*
}

Zhengzhou Tobacco Research Institute of CNTC, Zhengzhou 450001, China

taibol@163.com

\begin{abstract}
To investigate the relationship between spectral characteristics of tobacco cultivars and their nitrogen use characters, four tobacco cultivars with different nitrogen use efficiency were used in a ${ }^{15} \mathrm{~N}$ pot experiment. The result showed that, in the visible light range, the spectral reflectance was lower in higher nitrogen level (N2) than N1, while opposite in near infrared range. The spectral reflectance of K326 and HD were lower than ZY100 and NC89 in visible light range, which closely related to their higher chlorophyll content. Both the nitrogen utilization rate of basal fertilizer and topdressing fertilizer in HD and K326 were higher than that in ZY100 and NC89 under N1 and N2 levels. The basal fertilizer use efficiency was negatively correlated with $\rho 550$, and significantly positively correlated with RVI $(800,550)$, DVI $(800,550)$ and NDVI $(800,550)$ both in $\mathrm{N} 1$ and $\mathrm{N} 2$ level. The top dressed fertilizer use efficiency was significantly positively correlated with RVI $(800,550)$, DVI (800, $550)$ and NDVI $(800,550)$ in N1 level. Therefore, spectral characteristics can be an important method for diagnosing tobacco nitrogen metabolism characteristics.
\end{abstract}

Keywords: tobacco (Nicotiana tabacum L.), nitrogen use efficiency, spectral characteristics, nitrogen utilization.

\section{Introduction}

Tobacco is an important economic crop in China, but also an important model plant in science research. In the tobacco production, in order to get higher yield and income, excessive application of nitrogen fertilizer occurred from time to time, which caused potential threat to field ecosystem. Therefore, how to improve the tobacco nitrogen use efficiency has become a hot topic in tobacco nutrition study. Some studies showed that, crop nitrogen use efficiency closely related to cultivars, nitrogen levels and soil conditions and so on [1-3]. In certain ecological conditions, tobacco nitrogen use efficiency have significant differences among different genotypes, which closely related to plant nitrogen metabolism and nitrogen uptake and use efficiency [4-6].

In recent years, the use of remote sensing technique for real-time monitoring and plant nutrition diagnosis has become a hot topic in the application of remote sensing in 
agriculture. Hyperspectral technology, has some advantages such as wide spectrum range, high resolution, and large amount of data [7]. Through spectral changes monitoring, the relationship between spectra reflectance of crops and the leaf area index, aboveground biomass, chlorophyll content can be studied, which can provide basis for crop growth monitoring and yield estimation. [8-10]. Study showed that, crop nutrition condition closely related to spectral characteristics, and the crop spectra reflectance had significant differences under different nitrogen levels [11-12]. The relationship between leaf nitrogen accumulation and ratio of near infrared and green band $\mathrm{R}_{810} / \mathrm{R}_{560}$ was established, to monitor nitrogen nutrition of rice [13]. Tobacco nitrogen use efficiency have significant difference among different cultivars, however, the relationship between spectral characteristics and nitrogen utilization of different varieties was rarely reported. In this study, pot experiment was carried out to study the spectral characteristics of different nitrogen efficiency tobacco cultivars under different nitrogen levels and their relationship with nitrogen utilization, so as to provide theoretical basis for breeding and nutrient management.

\section{Materials and Methods}

\subsection{Experimental Design}

A ${ }^{15} \mathrm{~N}$ tracer pot experiment was performed in the greenhouse of Zhengzhou Tobacco Research Institute of China National Tobacco Corporation, Zhenzhou, China, from April to August (growing season) in 2012. Four cultivars, K326, Zhongyan 100 (ZY100), Hongda (HD) and NC89 were employed in the experiment under two nitrogen levels, $\mathrm{N} 1\left(1.0 \mathrm{~g} \mathrm{pot}^{-1}\right)$ and $\mathrm{N} 2\left(3.0 \mathrm{~g} \mathrm{pot}^{-1}\right)$, respectively.

Isotope fertilizer were ammonium nitrate ${ }^{15} \mathrm{~N}$ double labeled (abundance of 10\%) and ${ }^{15} \mathrm{~N}$ potassium nitrate (abundance of $10 \%$ ), which provided by Shanghai Research Institute of Chemical Industry. In ten pots, ${ }^{15} \mathrm{~N}$ ammonium nitrate fertilizer were applied before transplanting, and common potassium nitrate fertilizer were top dressed. In other ten pots, the order of fertilizer was opposite. Seventy percent N, all $\mathrm{P}_{2} \mathrm{O}_{5}$ and part of the $\mathrm{K}_{2} \mathrm{O}$ fertilizers were applied before transplanting. Other parts of the $\mathrm{N}$ and $\mathrm{K}_{2} \mathrm{O}$ was top dressed as potassium nitrate at the resettling growth stage. Each treatment had 20 pots, wherein each pot contained $15 \mathrm{~kg}$ soil.

\subsection{Measure Items and Methods}

At the vigorous growth stage (60 days after transplanting) and maturity stage ( 85 days after transplanting), the spectral characteristics was determined with ASD FieldSpec Hand-Held (AnalyticalSpectral Device, USA). Meanwhile, the tobacco plants were sampled for determination of dry weight and nitrogen content.

The chlorophyll content was measured by the method as described by Porra et al [14]. The ${ }^{15} \mathrm{~N}$ samples were analyzed by $\mathrm{ZHT}_{2} \mathrm{O}_{2}$ mass spectrometer in Academy of Agriculture and Forestry of Hebei Province. 


\subsection{Data Analysis}

Using Microsoft Excel 2010 and DPS (Data Processing System) for data processing and statistical analysis. $\operatorname{RVI}(\lambda 1, \lambda 2)=\rho \lambda 1 / \rho \lambda 2 ; \operatorname{DVI}(\lambda 1, \lambda 2)=|\rho \lambda 1-\rho \lambda 2| ; \operatorname{NDVI}(\lambda 1$, $\lambda 2)=|\rho \lambda 1-\rho \lambda 2| /(\rho \lambda 1+\rho \lambda 2)$; among them, $\rho$ was reflectance, $\lambda$ was wave length.

\section{$3 \quad$ Results and Analysis}

\subsection{Spectral Characteristics of Tobacco Cultivars with Different Nitrogen Efficiency}

Figure 1 showed the spectral reflectance of different tobacco cultivars in two nitrogen levels. In the visible light range, the chlorophyll absorption of visible light formed obvious "green peak" at 500-600nm. From 670-760nm, the spectral reflectance increased rapidly with the increasing wavelength, and formed high reflection platform in the near infrared range 780-1050 nm. Tobacco leaf spectral reflectance showed significant differences under different nitrogen levels. In the visible light range, the spectral reflectance was lower in higher nitrogen level (N2) than N1, while opposite in near infrared range. Compared among different cultivars, the spectral reflectance of K326 and HD were lower than ZY100 and NC89 in visible light range, which closely related to their higher chlorophyll content. In the near infrared range, the spectral reflectance of four cultivars showed the different order in $\mathrm{N} 1$ and N2, which showed the difference of response to nitrogen level among different cultivars.
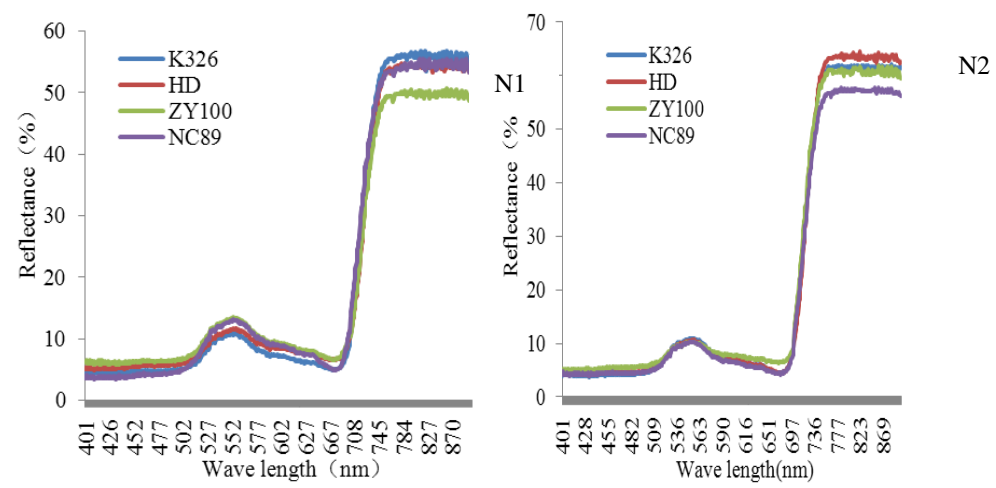

Fig. 1. Changes of spectral characteristics of four tobacco cultivars with different nitrogen efficiency

\subsection{Nitrogen Use Efficiency of Different Tobacco Cultivars}

${ }^{15} \mathrm{~N}$ tracer test results (Table1) showed that, 15.54\% 21.72\% nitrogen accumulation amount derived from fertilizer, and 78.28\% 84.46\% from soil at N1 level; while at N2 level, they were $45.04 \% \sim 48.29 \%$ and $51.71 \% \sim 54.96 \%$, respectively. Therefore, tobacco plant absorbed more nitrogen from soil under lower nitrogen level, while more 
nitrogen from fertilizer under higher nitrogen level. Compared among different cultivars, the proportion of nitrogen accumulation from fertilizer of ZY100 was higher than other cultivars under both $\mathrm{N} 1$ and N2 levels.

According to nitrogen accumulation amount, all the nitrogen from fertilizer, soil and total amount were higher in HD and K326 than that in ZY100 and NC89 under both N1and N2 levels.

Table 1. Nitrogen use efficiency of different tobacco cultivars

\begin{tabular}{|c|c|c|c|c|c|c|c|c|c|c|}
\hline \multirow{4}{*}{$\begin{array}{c}\text { Nitrog } \\
\text { en } \\
\text { level }\end{array}$} & \multirow{4}{*}{ Cultivar } & \multirow{4}{*}{$\begin{array}{c}\text { TNUA } \\
\left(\text { mg.plant }{ }^{-1}\right)\end{array}$} & \multicolumn{6}{|c|}{ NDFF } & \multirow{2}{*}{\multicolumn{2}{|c|}{ NDFS }} \\
\hline & & & \multicolumn{2}{|c|}{ NDFBF } & \multicolumn{2}{|c|}{ NDFTF } & \multicolumn{2}{|c|}{ Total } & & \\
\hline & & & NUA & NUR & NUA & NUR & NUA & NUR & NUA & NUR \\
\hline & & & $\left(\mathrm{mg} \cdot\right.$ plant $\left.^{-1}\right)$ & $\%$ & $\left(\mathrm{mg} \cdot\right.$ plant $\left.^{-1}\right)$ & $\%$ & $\left(\mathrm{mg} \cdot\right.$ plant $\left.^{-1}\right)$ & $\%$ & $\left(\mathrm{mg} \cdot\right.$ plant $\left.^{-1}\right)$ & $\%$ \\
\hline \multirow{4}{*}{ N1 } & $\mathrm{HD}$ & 2808.96 & 307.31 & 10.94 & 199.02 & 7.09 & 506.33 & 18.03 & 2302.63 & 81.97 \\
\hline & K326 & 2409.47 & 302.21 & 12.54 & 162.21 & 6.73 & 464.42 & 19.27 & 1945.06 & 80.73 \\
\hline & ZY100 & 2046.39 & 278.28 & 13.60 & 166.15 & 8.12 & 444.43 & 21.72 & 1601.96 & 78.28 \\
\hline & NC89 & 2314.79 & 212.10 & 9.16 & 147.60 & 6.38 & 359.71 & 15.54 & 1955.09 & 84.46 \\
\hline \multirow{4}{*}{$\mathrm{N} 2$} & HD & 2917.23 & 839.79 & 28.79 & 513.06 & 17.59 & 1352.84 & 46.37 & 1564.38 & 53.63 \\
\hline & K326 & 2784.23 & 822.12 & 29.53 & 431.77 & 15.51 & 1253.89 & 45.04 & 1530.34 & 54.96 \\
\hline & ZY100 & 2419.85 & 740.06 & 30.58 & 428.61 & 17.71 & 1168.67 & 48.29 & 1251.19 & 51.71 \\
\hline & NC89 & 2279.63 & 655.36 & 28.75 & 418.94 & 18.38 & 1074.30 & 47.13 & 1205.32 & 52.87 \\
\hline
\end{tabular}

TNUA: total nitrogen uptake amount; NUA: nitrogen uptake amount; NUR: nitrogen uptake ratio; NDFF: nitrogen derived from fertilizer; NDFBF: nitrogen derived from basal fertilizer; NDFTF: nitrogen derived from topdressing fertilizer; NDFS: nitrogen derived from soil.

The nitrogen use efficiency was calculated by ${ }^{15} \mathrm{~N}$ technique in different treatments (Table 2). Under N1 level, the utilization rate of basal fertilizer were 30.30\% 43.90\%, and topdressing fertilizer were $49.20 \% \sim 66.30 \%$; while under $\mathrm{N} 2$ level, that were $31.21 \% \sim 39.99 \%$ and $46.55 \% \sim 57.01 \%$, respectively. The nitrogen utilization rate of topdressing fertilizer was significantly higher than that of basal fertilizer. Compared among different cultivars, both the nitrogen utilization rate of basal fertilizer and topdressing fertilizer aligned as HD and K326> ZY100 and NC89 under N1 and N2 levels.

Also it showed that, the nitrogen residual rate of topdressing fertilizer were lower than that in basal fertilizer. Compared among different cultivars, both the soil residual rate and loss rate were lower in HD, which may be related to the well root growth and higher nitrogen use efficiency in this cultivar. 
Table 2. Nitrogen use efficiency of different tobacco cultivars

\begin{tabular}{|c|c|c|c|c|c|c|c|c|}
\hline \multirow{2}{*}{$\begin{array}{c}\text { Nitrogen } \\
\text { level }\end{array}$} & \multirow{2}{*}{ Cultivar } & \multirow{2}{*}{$\begin{array}{l}\text { Fertilization } \\
\text { time }\end{array}$} & \multicolumn{4}{|c|}{ Uptake (\%) } & \multirow{2}{*}{$\begin{array}{l}\text { Residual ratio } \\
\quad(\%)\end{array}$} & \multirow{2}{*}{$\begin{array}{c}\text { Loss } \\
\text { ratio } \\
(\%) \\
\end{array}$} \\
\hline & & & Root & Stem & Leaf & Total & & \\
\hline \multirow{8}{*}{ N1 } & \multirow{2}{*}{$\mathrm{HD}$} & $\mathrm{BF}$ & 3.96 & 5.36 & 34.58 & 43.90 & 45.13 & 10.97 \\
\hline & & $\mathrm{TF}$ & 6.00 & 9.87 & 50.47 & 66.30 & 20.76 & 12.94 \\
\hline & \multirow{2}{*}{ K326 } & $\mathrm{BF}$ & 5.85 & 4.87 & 32.45 & 43.17 & 46.22 & 10.61 \\
\hline & & $\mathrm{TF}$ & 10.37 & 10.26 & 33.44 & 54.07 & 22.35 & 23.58 \\
\hline & \multirow{2}{*}{ ZY100 } & $\mathrm{BF}$ & 3.50 & 6.61 & 29.65 & 39.75 & 35.37 & 24.88 \\
\hline & & $\mathrm{TF}$ & 5.05 & 7.65 & 42.68 & 55.38 & 20.74 & 23.87 \\
\hline & \multirow{2}{*}{ NC89 } & $\mathrm{BF}$ & 4.06 & 3.56 & 22.68 & 30.30 & 52.99 & 16.71 \\
\hline & & $\mathrm{TF}$ & 7.57 & 6.18 & 35.46 & 49.20 & 13.83 & 36.97 \\
\hline \multirow{8}{*}{ N2 } & \multirow{2}{*}{$\mathrm{HD}$} & BF & 3.03 & 6.14 & 30.82 & 39.99 & 33.05 & 26.96 \\
\hline & & $\mathrm{TF}$ & 5.79 & 10.03 & 41.18 & 57.01 & 14.20 & 28.79 \\
\hline & \multirow{2}{*}{ K326 } & BF & 3.81 & 5.05 & 30.29 & 39.15 & 43.11 & 17.74 \\
\hline & & $\mathrm{TF}$ & 6.82 & 8.38 & 32.78 & 47.96 & 18.55 & 33.49 \\
\hline & \multirow{2}{*}{ ZY100 } & BF & 3.10 & 4.93 & 27.20 & 35.24 & 40.03 & 24.73 \\
\hline & & $\mathrm{TF}$ & 6.09 & 8.02 & 33.51 & 47.62 & 17.56 & 34.82 \\
\hline & \multirow{2}{*}{ NC89 } & BF & 4.97 & 4.20 & 22.04 & 31.21 & 39.53 & 29.26 \\
\hline & & $\mathrm{TF}$ & 8.71 & 7.88 & 29.96 & 46.55 & 14.28 & 39.17 \\
\hline
\end{tabular}

\subsection{The Correlation Analysis between Vegetation Index and Nitrogen Metabolism Index}

It showed that (Table 3 ), the chlorophyll content was significantly negatively correlated with $\rho 550$, and significantly positively correlated with RVI $(800,550)$, DVI $(800,550)$ and NDVI $(800,550)$ in $\mathrm{N} 1$ level. The total nitrogen uptake amount was significantly negatively correlated with $\rho 550$, and significantly positively correlated with RVI $(800,550)$, DVI $(800,550)$ and NDVI $(800,550)$ in N2 level. The BFUE was negatively correlated with $\rho 550$, and significantly positively correlated with RVI $(800,550)$, DVI $(800,550)$ and NDVI $(800,550)$ both in N1 and N2 level. The TFUE was significantly positively correlated with RVI $(800,550)$, DVI $(800,550)$ and NDVI $(800,550)$ in N1 level. 
Table 3. The correlation index between some vegetation index and Chlorophyll, TNUA, BFUE, and TFUE

\begin{tabular}{ccccccc}
\hline Nitrogen level & Index & $\rho 550$ & $\rho 800$ & RVI(800,550) & DVI(800,550) & NDVI(800,550) \\
\hline \multirow{2}{*}{ N1 } & $\begin{array}{c}\text { Chlorophyll } \\
\text { content }\end{array}$ & $-0.98^{* *}$ & 0.81 & $0.97^{*}$ & $0.89^{*}$ & $0.97^{* *}$ \\
& TNUA & -0.85 & 0.4 & 0.77 & 0.53 & 0.73 \\
& BFUE & -0.84 & $0.96^{* *}$ & $0.90^{*}$ & $0.97^{* *}$ & $0.93^{*}$ \\
& TFUE & -0.84 & 0.84 & $0.90^{*}$ & $0.87^{*}$ & $0.88^{*}$ \\
& $\begin{array}{c}\text { Chlorophyll } \\
\text { content }\end{array}$ & -0.44 & 0.65 & 0.58 & 0.63 & 0.55 \\
& TNUA & $-0.87^{*}$ & $0.92^{*}$ & $0.92^{*}$ & $0.92^{*}$ & $0.91^{*}$ \\
& BFUE & $-0.96^{* *}$ & $0.97 * *$ & $0.98^{* *}$ & $0.97 * *$ & $0.97 * *$ \\
& TFUE & 0.59 & 0.78 & 0.72 & 0.77 & 0.7 \\
\hline
\end{tabular}

TNUA: total nitrogen uptake amount; BFUE: basal fertilizer use efficiency; TFUE: topdressing fertilizer use efficiency.

\section{Conclusion and Discussion}

Tobacco leaf spectral reflectance showed significant differences under different nitrogen levels, which showed the difference of response to nitrogen level among different cultivars. Studies showed that the spectral reflectance closely related to chlorophyll content [15-16]. In the visible light range, the tobacco cultivar with higher nitrogen use efficiency showed lower spectral reflectance, which closely related to their higher chlorophyll content.

The canopy spectral characteristics under different nitrogen conditions were analyzed in previous studies [7,11]. Tang et al [17] had illustrated that the spectral difference were clear for the canopy and leaves of rice under different nitrogen levels. In this study, the spectral reflectance in the visible light range was lower in higher nitrogen level, which consistent with previous studies. Some studies showed that crop nitrogen nutrition condition can determined using canopy spectral, however, the relationship between canopy spectral characteristics and plant nitrogen use was rarely reported. In this study, the basal fertilizer use efficiency was negatively correlated with $\rho 550$, and significantly positively correlated with RVI $(800,550)$, DVI $(800,550)$ and NDVI $(800,550)$ both in N1 and N2 level. The topdressing fertilizer use efficiency was significantly positively correlated with RVI $(800,550)$, DVI $(800,550)$ and NDVI $(800,550)$ in N1 level. Therefore, spectral characteristics can be an important method for diagnosing tobacco nitrogen metabolism characteristics. 
Acknowledgement. This study was supported by the National Natural Science Foundation of China (31101120) and the key Science and Technology Program of Henan Province, China (102101110600).

\section{References}

1. Serret, M.D., Ortiz-Monasterio, I., Pardo, A., et al.: The Effects of Urea Fertilisation and Genotype on Yield, Nitrogen Use Efficiency, $15^{\mathrm{N}}$ and $13^{\mathrm{C}}$ in Wheat. Annals of Applied Biology 153(2), 243-257 (2008)

2. Gallais, A., Hirel, B.: An Approach to the Genetics of Nitrogen Use Efficiency in Maize. Journal of Experimental Botany 55(396), 295-306 (2004)

3. Gill, S., Abid, M., Azam, F.: Root Induced Changes in Potential Nitrification and Nitrate Reductase Activity of the Rhizospheric Soil of Wheat (triticum aestivum L) and Chichpea (cicer arietinum L. Pakistan Journal of Botany 38(4), 991-997 (2006)

4. Juan, M.R., Rosa, M.R., Luis, M.C., et al.: Grafting to Improve Nitrogen-use Efficiency Traits in Tobacco Plants. Journal of the Science of Food and Agriculture 86(6), 1014-1021 (2006)

5. Kruse, J., Kopriva, S., Hansch, R., et al.: Interaction of Sulfur and Nitrogen Nutrition in Tobacco (Nicotiana tabacum) Plants: Significance of Nitrogen Source and Root Nitrate Reductase. Plant Biology 9(5), 638-646 (2007)

6. Tang, W.J., He, F.F., Zhou, J.H., He, W., Yang, Z.Y., Yang, H.Q., Xiao, Z.X.: Transformation Law of Different Formal Nitrogen Fertilizer in Paddy Field and its Effect on Growth and Nicotine Content of Flue-cured Tobacco. Crop Research 23(1), 30-34 (2009) (in Chinese)

7. Wang, L., Bai, Y.L.: Correlation Between Corn Leaf Spectral Reflectance and Leaf Total Nitrogen and Chlorophyll Content under Different Nitrogen Level. Scientia Agricultura Sinica 38(11), 2268-2276 (2005)

8. Feng, W., Zhu, Y., Tian, Y.C., et al.: Monitoring Canopy Leaf Pigment Density in Wheat with Hyperspectral Remote Sensing. Acta Ecologica Sinica 28(10), 4902-4911 (2008) (in Chinese)

9. Huang, C.Y., Wang, D.W., Yan, J., Zhang, Y.X., Cao, L.P., Cheng, C.: Monitoring of Cotton Canopy Chlorophyll Density and Leaf Nitrogen Accumulation Status by Using Hyperspectral Data. Acta Agronomica Sinica 33(6), 931-936 (2007) (in Chinese)

10. Royo, C., Aparicion, N., Villegas, D., Casadesus, J., Monneveux, P., Araus, J.L.: Usefulness of Spectral Reflectance Indices as Durum Wheat Yield Predictors Under Contrasting Mediterranean Conditions. International Journal of Remote Sensing 24(22), 4403-4419 (2003)

11. Dai, H., Hu, C.S., Cheng, Y.S., Song, W.C.: Correlation Between Agronomic Parameters and Spectral Vegetation Index in Winter Wheat Under Different Nitrogen Levels. Agricultural Research in the Arid Areas 23(4), 16-22 (2005) (in Chinese)

12. Sun, H., Li, M.Z., Zhang, Y.E., Zhao, Y., Wang, H.H.: Spectral Characteristics of Corn Under Different Nitrogen Treatments. Spectroscopy and Spectral Analysis 30(3), 715-719 (2010) (in Chinese)

13. Xue, L.H., Cao, W.X., Luo, W.H., Jiang, D., Meng, Y.L., Zhu, Y.: Diagnosis of Nitrogen Statues in Rice Leaves with the Canopy Spectral Reflectance. Sci Agric Sinica 36(7), 807-812 (2003) (in Chinese) 
14. Porra, R.J., Thompson, W.A., Kriedemann, P.E.: Determination of Accurate Extinction Coefficients and Simultaneous Equations for Assaying Chlorophylls a and b Extracted with Four Different Solvents: Verification of the Concentration of Chlorophyll Standards by Atomic Absorption Spectroscopy. Biochimica. Et. Biophysica. Acta. 975, 384-394 (1989)

15. Li, X.Y., Liu, G.X., Yang, Y.F., Zhao, C.H., Yu, Q.W., Song, S.X.: Relationship Between Hyperspectra Parameters and Physiological and Biochemical Indexes of Flue-cured Tobacco Leaves. Scientia Agricultura Sinica 40(5), 987-994 (2007)

16. Meng, Z.Q., Hu, C.S., Cheng, Y.S.: Study on Correlation Between Chlorophyll Density of Winter Wheat and Hyperspectral Data. Agricultural Research in the Arid Areas 25(6), 74-79 (2007) (in Chinese)

17. Tang, Y.L., Wang, R.C., Huang, J.F., Kong, W.S., Cheng, Q.: Hyperspectral Data and Their Relationships Correlative to the Pigment Contents for Rice Under Different Nitrogen Support Level. Journal of Remote Sensing 8(2), 185-192 (2004) (in Chinese) 